\title{
Public Knowledge and Attitudes Regarding Antibiotic Use in South Korea
}

\author{
Kim, So Sun ${ }^{1} \cdot$ Moon, Seongmi ${ }^{2} \cdot$ Kim, Eun Jung ${ }^{3}$ \\ ${ }^{1}$ Professor, College of Nursing · Researcher, The Nursing Policy Research Institute, Yonsei University, Seoul \\ ${ }^{2}$ Assistant Professor, Department of Nursing, University of Ulsan, Ulsan \\ ${ }^{3}$ Full-time Lecturer, College of Nursing, Eulji University, Seongnam, Korea
}

Purpose: This study was conducted to examine public level of knowledge and attitudes regarding antibiotic use and potential drug resistance. Methods: A cross-sectional face-to-face survey of 1,177 residents aged 18 or over was conducted in Korea. A quota sampling method was used. Results: Most respondents (70\%) did not know that antibiotics are ineffective in treating coughs and colds. Two-thirds of the respondents were unaware of the conditions under which antibiotic resistance occurs, despite understanding the concept of resistance. Lower education level and older age were independently associated with inadequate knowledge. Lower education level, older age, inadequate knowledge and no exposure to the education campaign were independently associated with poor attitude. Conclusion: The results of this study demonstrate that the general public has misunderstandings and a lack of knowledge with regard to antibiotic use, despite a national educational campaign. However, the campaign may have had an effect on the public's attitudes towards antibiotics.

Key words: Anti-bacterial agents, Education, Knowledge, Attitude

\section{INTRODUCTION}

The era of antibiotics transformed the treatment and outcome of infectious diseases, but the overuse and misuse of antibiotics has generated unimaginable problems, primarily antibiotic resistance (Dancer, 2004; WHO, 2001; You et al., 2008). People infected with an antibiotic-resistant organism are more likely to have longer hospital stays and require treatment with second- or third-line drugs that may be less effective, more toxic and more expensive (Farrell et al., 2005; Levy, 2005).

Efforts to reduce antibiotic resistance must include educating the public on the appropriate use of antibiotics. It would be a campaign addressing the fact that antibiotics do not cure common coughs or colds. Several countries have undertaken national campaigns to modify the public's misconceptions regarding the effectiveness of antibiotics, to promote appropriate antibiotic use and prevent the development of antibiotic resistance (Andre, Vernby, Berg, \& Lundborg, 2010; Curry et al., 2006; McNulty, Boyle, Nichols, Clappison, \& Davey, 2007a; Woodhead \& Finch, 2007; Wutzke et al., 2006).

Korea had the sixth highest antibiotic usage in OECD countries according to 2003 health insurance claim data in Korea (Kim et al., 2006). A Korean national study in 2004 (Kim et al., 2004) found that $66 \%$ of hospital doctors and $53 \%$ of primary doctors prescribed antibiotics for upper respiratory infections (URIs) and two-thirds of the general public believed that antibiotics were helpful in treating the common cold. It is necessary to encourage the general public not to ask for antibiotics without sake and advise the public that antibiotics do not work on common colds and coughs (McNulty et al., 2007a).

\footnotetext{
*This study was supported by the research fund from the Korea Food and Drug Administration (KFDA) in 2007.

Address reprint requests to: Kim, Eun Jung

College of Nursing, Eulji University, 212 Yangji-dong, Sujeong-gu, Seongnam 461-713, Korea

Tel: +82-31-740-7398 Fax:+82-31-740-7359 E-mail:ejerkim@eulji.ac.kr

Received: April 12,2011 Revised: April 30,2011 Accepted: December 19,2011
} 
To fight against improper use of antibiotics and the associated resistance problems, the Korea Food \& Drug Administration (KFDA) organized a National Antimicrobial Resistance Experts Committee (NAREC) in 2003. Since then, the NAREC has implemented a number of national educational campaigns on the appropriate use of antibiotics in various ways targeting the general public. These educational campaigns included the distribution of leaflets and CD-ROMs on appropriate antibiotic use and television addresses on antibiotic resistant bacteria (Kwon et al., 2006), but the general public's knowledge of and attitudes toward antibiotics including effectiveness of the campaigns conducted by KFDA have never been investigated since its launching in 2004.

Therefore, we conducted this study to assess the general public' knowledge of and attitudes toward antibiotic use.

\section{METHODS}

\section{Participants}

This was a cross-sectional face-to-face survey of a sample of 1,500 non-institutional residents in Korea. A sample size of 1,100 would give to a confidence interval of margin of error of $3 \%$ and confidence level of $95 \%$ in the determination of prevalence in population; therefore, 1,500 were enrolled by considering the dropout rate. Participants were selected using a quota sampling method with strata defined as region using data from the Korea National Census of 2005. The following numbers of participants were selected from six major metropolitan cities and a province taking into consideration the population size and regional location: Gangwon-do, 100; Seoul, 700; Busan, 250; Daegu, 150; Incheon, 150; Daejeon, 100; Gwangju, 100 participants. The participants were adults aged 18 and older irrespective of specific age and gender.

\section{Materials and procedures}

The questionnaire was developed by researchers with reference to the US Centers for Disease Control and Prevention (CDC) clinical guidelines (2010) on appropriate antibiotic use for the treatment of URIs and related recommendations from other sources. The questionnaire was validated by 4 experts, such as 1 physician, 1 pharmacy professor and 2 nursing professors. The final questionnaire was re- vised based on their recommendations.

The questionnaire included questions regarding knowledge and attitudes about the appropriate use of antibiotics and potential antibiotic resistance.

The scale that measured knowledge of the cause of common cold and antibiotic use for treatment of symptoms associated with upper respiratory tract infections comprised of 15 -items. Each item was to choose one from the following 3 options: yes, no, and do-not-know. The knowledge score was determined by calculating the number of correct answers to these 15 items and the answers with do-not-know were added into incorrect one. Cronbach's alpha was .80 in the present study.

The scale about attitude regarding antibiotics use in the management of common cold were comprised of 7-items and each item was to be answered either agree or disagree. Cronbach's alpha of the scale was .64 in the present study.

In addition, the respondents were asked whether they had had any access to the KFDA-sponsored antibiotic education campaigns through mass media such as a newspaper, television, poster, leaflet, or internet, and so on as a part of evaluation on the governmental efforts.

The respondent's demographic data included gender, age, level of education, household income, employment, and marital status.

The data were collected from September to October 2007 with the response rate of $78.5 \%$. The responses from 1,177 participants were used in analysis.

\section{Data analysis}

Descriptive statistics of the respondents' knowledge and attitudes regarding antibiotic use and bacterial resistance were reported. The chi-squared test was used to examine the association between categorical knowledge (inadequate/adequate) and categorical attitude (poor/good). Associations of demographic variables (gender, age, family income level, education level, employment and marital status) including an exposure to educational campaigns regarding antibiotic use with knowledge and attitudes were first evaluated using a univariate analysis by chi-squared test. Factors that were significantly associated in the univariate analysis were further analyzed using a stepwise multiple logistic regression. The significance level was set at $p<.05$. All analyses were performed using SPSS for Windows, version 12.0 (SPSS Inc., Chicago, IL, USA). 


\section{RESULTS}

\section{Knowledge of antibiotic use and resistance}

Fifteen questions assessed knowledge related to appropriate antibiotic use and resistance. Over two-thirds (76.5\%) of respondents knew that the majority of colds and coughs are caused by viruses; however, most respondents were not aware of the role of antibiotics in treating viral infections. Just $18.5 \%$ of respondents disagreed with the statement that antibiotics work on most sore throats and only $30.1 \%$ of respondents correctly answered questions about using antibiotics to treat coughs and colds. Thirty-one percent of respondents correctly disagreed that antibiotics can kill viruses. Over half (57.2\%) did not know that antibiotics can kill bacteria that normally live on the skin and in the gut. Sixty-five percent of respondents had correct knowledge of the meaning of antibiotic resistance. However, many respondents were misinformed regarding the reduced effectiveness of treatment if the full course of antibiotic treatment was not completed and the potential to spread antibiotic resistant bacteria (Table 1).

\section{Attitudes toward antibiotic use}

Seven questions assessed attitudes toward antibiotic use. Questions 1 through 5 measured negative attitude, while questions 6 and 7 measured positive attitude. Thirty percent of respondents said that they had requested antibiotics for treating a cold and $48.2 \%$ of respondents believed that antibiotics helped them recover from the cold more quickly. Similarly, 542 respondents (46.9\%) said they had taken unconsumed antibiotics from previously filled prescriptions without first consulting a doctor, and $77.6 \%$ of respondents stopped taking the medication when they felt better. Additionally, only $22.4 \%$ of respondents confirmed that the prescribed medication included an antibiotic and 19.9\% were aware of which of the prescribed drugs was an antibiotic (Table 2).

\section{Association between knowledge of and attitudes toward antibiotic use}

Associations between knowledge of and attitudes toward antibi-

Table 1. Responses to Questions regarding Knowledge of Antibiotic Use

\begin{tabular}{|c|c|c|}
\hline Questions & Correct response & No. of correct $(\%)$ \\
\hline Viruses cause most coughs and colds & Agree & $896(76.5)$ \\
\hline Antibiotics work on most coughs and colds & Disagree & $353(30.1)$ \\
\hline Antibiotics work on most sore throats & Disagree & $217(18.5)$ \\
\hline Antibiotics can kill bacteria & Agree & $540(46.1)$ \\
\hline Antibiotics can kill viruses & Disagree & $359(30.6)$ \\
\hline Bacteria that normally live on the skin and in the gut are good for health & Agree & $847(72.3)$ \\
\hline Antibiotics do not kill the bacteria that normally live on the skin and in the gut & Disagree & $502(42.8)$ \\
\hline Antibiotic resistance means that bacteria would not be killed by antibiotics & Agree & $760(64.8)$ \\
\hline Infection by antibiotic resistant bacteria cannot be easily cured or cannot be cured & Agree & $759(64.8)$ \\
\hline If antibiotics are taken for a long time, bacteria become more resistant to antibiotics & Agree & $822(70.1)$ \\
\hline If antibiotics are taken less than the prescribed dose bacteria become less resistant to antibiotics & Disagree & $498(42.5)$ \\
\hline If twice the prescribed dose is taken the effects of antibiotics are more rapid & Disagree & $789(67.3)$ \\
\hline The prescribed course of antibiotics can be terminated if the symptoms improve & Disagree & 361 (30.8) \\
\hline Antibiotic resistance can spread between bacteria & Agree & $387(33.0)$ \\
\hline Antibiotics have no side-effects & Disagree & $826(70.5)$ \\
\hline
\end{tabular}

Table 2. Responses to Questions regarding Attitudes toward Antibiotic Use

\begin{tabular}{|c|c|c|}
\hline Questions & Appropriateness & No. of agree (\%) \\
\hline If I catch a cold, I ask for an antibiotic prescription to prevent my symptoms from getting worse & Inappropriate & $349(30.0)$ \\
\hline I believe that antibiotics cure my cold faster & Inappropriate & $561(48.2)$ \\
\hline I take left-over antibiotics when I have similar flu symptoms & Inappropriate & $542(46.9)$ \\
\hline I would stop taking the prescribed antibiotics if I got better & Inappropriate & $891(77.6)$ \\
\hline I prefer a shot to an oral medicine if antibiotics are needed & Inappropriate & $497(43.8)$ \\
\hline I know which medicines are the antibiotics when I take cold medicines & Appropriate & 231 (19.9) \\
\hline
\end{tabular}


otic use were determined using the chi-squared test. A knowledge score was determined by calculating the number of correct answers to the 15 questions that tested participants' knowledge of antibiotic use. The mean knowledge score was 7.7 (SD 3.58) and the median was 7.5. Inadequate and adequate knowledge were defined as a total knowledge score of 0-7 and 8-15, respectively.

Respondents who had adequate knowledge of antibiotics were more likely to have a positive attitude toward the use of antibiotics. Thirty-eight percent of respondents with inadequate knowledge agreed with the statement, "When I get a cold, I should take antibiotics to prevent getting a more serious illness." Fifty-seven percent of respondents with lower knowledge scores responded incorrectly to the statement "When I have a cold, antibiotics help me to get better more quickly." Respondents with higher knowledge scores were more likely to confirm whether or not a prescription contained antibiotics (26.0\%) and understood which of the prescription drugs was an antibiotic (22.2\%) (Table 3).

\section{Factors significantly associated with public knowledge and attitudes regarding antibiotic use}

Five variables (age, education, marital status, employment and family income level) showed a significant association with the respondents' knowledge regarding antibiotic use, according to the chisquared test. Exposure to an educational campaign was not significantly associated with knowledge of antibiotic use. However, expo- sure to an educational campaign was an important variable to researchers, along with five other variables that were analyzed using a step-wise multiple logistic regression to determine their independent influences on adequate knowledge of antibiotic use. Age and education were shown to be significant predictors. Compared to respondents aged 18-39, the level of adequate knowledge of antibiotics was low in those aged 40-59 (OR 0.53; 95\% CI 0.37-0.76) and $\geq 60$ (OR 0.29; 95\% CI 0.16-0.55). Respondents who had graduated from college were 2.39-fold (95\% CI 1.12-5.09) more likely to be aware of appropriate antibiotic use than respondents with a primary-level education. Respondents with a family income of 2-4 million won per month were 1.38-fold (95\% CI 1.01-1.88) more likely to be aware of appropriate antibiotic use than respondents with a family income below 2 million won per month (Table 4).

An attitude score was determined by calculating the number of appropriate answers to seven questions concerning attitudes toward antibiotic use. The mean attitude score was 2.97 (SD 1.53) and the median was 3.5. Attitude scores of 0-3 and 4-7 were considered poor and good, respectively. Four variables (age, education, knowledge of antibiotic use and exposure to an educational campaign) were significantly associated with respondents' attitudes according to the chisquare test. A step-wise multiple logistic regression was conducted on these four variables; three were shown to be significant predictors. Exposure to an educational campaign (OR 1.74; 95\% CI 1.18-2.57) and adequate knowledge of antibiotic use (OR 1.53; 95\% CI 1.17-2.02) were independently associated with good attitudes. Compared to re-

Table 3. Association between Knowledge of and Attitudes toward Antibiotic Use

\begin{tabular}{|c|c|c|c|c|}
\hline \multirow[b]{2}{*}{ Attitudes } & & \multicolumn{2}{|c|}{ Knowledge score n (\%) } & \multirow[b]{2}{*}{$x^{2}(p)$} \\
\hline & & $\begin{array}{c}<8 \\
n=523\end{array}$ & $\begin{array}{c}\geq 8 \\
n=649\end{array}$ & \\
\hline \multirow{2}{*}{$\begin{array}{l}\text { If I catch a cold, I ask for an antibiotic prescription to prevent my symptoms } \\
\text { from getting worse }\end{array}$} & Disagree & $320(62.1)$ & $491(76.4)$ & \multirow[t]{2}{*}{$27.57(<.001)$} \\
\hline & Agree & $195(37.9)$ & $152(23.6)$ & \\
\hline I believe that antibiotics cure my cold faster & Disagree & $222(43.0)$ & $382(59.2)$ & $30.15(<.001)$ \\
\hline \multirow[t]{2}{*}{ I take left-over antibiotics when I have similar flu symptoms } & Disagree & $265(52.0)$ & $347(54.1)$ & \multirow[t]{2}{*}{$0.54(.476)$} \\
\hline & Agree & $245(48.0)$ & $294(45.9)$ & \\
\hline \multirow[t]{2}{*}{ I would stop taking the prescribed antibiotics if I got better } & Disagree & $121(24.0)$ & $136(21.3)$ & \multirow[t]{2}{*}{$1.23(.285)$} \\
\hline & Agree & $383(76.0)$ & $504(78.8)$ & \\
\hline \multirow[t]{2}{*}{ I prefer a shot to an oral medicine if antibiotics are needed } & Disagree & $262(53.1)$ & $375(58.8)$ & \multirow[t]{2}{*}{$3.59(.061)$} \\
\hline & Agree & $231(46.9)$ & $263(41.2)$ & \\
\hline I check to see if antibiotics are included within the prescribed cold medicines & Agree & $90(17.6)$ & $166(26.0)$ & $11.69(.001)$ \\
\hline \multirow[t]{2}{*}{ I know which medicines are antibiotics when I take cold medicines } & Disagree & $430(83.5)$ & $500(77.8)$ & \multirow[t]{2}{*}{$5.95(.017)$} \\
\hline & Agree & 85 (16.5) & 143 (22.2) & \\
\hline
\end{tabular}


Table 4. Factors Significantly Associated with Public Knowledge of Antibiotic Use

\begin{tabular}{|c|c|c|c|c|}
\hline & \multicolumn{2}{|c|}{$n(\%)$} & \multirow[b]{2}{*}{$\begin{array}{l}\text { Adjusted OR* } \\
\quad(95 \% \mathrm{Cl})\end{array}$} & \multirow[b]{2}{*}{$p$} \\
\hline & $\begin{array}{c}\text { Inadequate } \\
\text { knowledge }(<8) \\
(n=523)\end{array}$ & $\begin{array}{c}\text { Adequate } \\
\text { knowledge }(\geq 8) \\
(n=649)\end{array}$ & & \\
\hline \multicolumn{5}{|l|}{ Age (yr) } \\
\hline $18-39$ & $149(29.8)$ & $351(70.2)$ & 1 (Referent) & \\
\hline $40-59$ & $256(49.0)$ & $266(51.0)$ & $0.53(0.37-0.76)$ & $<.001$ \\
\hline$\geq 60$ & $112(79.4)$ & $29(20.6)$ & $0.29(0.16-0.56)$ & $<.001$ \\
\hline \multicolumn{5}{|l|}{ Education } \\
\hline$\leq$ Primary & 71 (83.5) & $14(16.5)$ & 1 (Referent) & \\
\hline Middle school & $61(73.5)$ & $22(26.5)$ & 0.68 (0.29-1.59) & .371 \\
\hline High school & $222(43.7)$ & $286(56.3)$ & $1.55(0.74-3.25)$ & .247 \\
\hline$\geq$ College & 159 (33.3) & $319(66.7)$ & $2.39(1.12-5.09)$ & .024 \\
\hline \multicolumn{5}{|c|}{ Family income (won) } \\
\hline$<2,000,000$ & $229(51.5)$ & $216(48.5)$ & 1 (Referent) & \\
\hline $\begin{array}{l}2,000,000 \\
-4,000,000\end{array}$ & $156(37.0)$ & $266(63.0)$ & $1.38(1.01-1.88)$ & .044 \\
\hline$>4,000,000$ & $138(45.2)$ & $167(54.8)$ & $1.14(0.81-1.61)$ & .457 \\
\hline \multicolumn{5}{|l|}{ Employment } \\
\hline $\begin{array}{l}\text { Unemployed/ } \\
\text { housewife }\end{array}$ & $116(66.7)$ & $58(33.3)$ & 1 (Referent) & \\
\hline Employed & $378(39.5)$ & $580(60.5)$ & $1.36(0.91-2.03)$ & .134 \\
\hline \multicolumn{5}{|l|}{ Marital status } \\
\hline Married & $392(50.9)$ & $378(49.1)$ & 1 (Referent) & \\
\hline Unmarried & $119(31.4)$ & $260(68.6)$ & $1.30(0.90-1.88)$ & .169 \\
\hline \multicolumn{5}{|c|}{ Exposure to campaign } \\
\hline No & $470(45.5)$ & $562(54.5)$ & 1 (Referent) & \\
\hline Yes & $52(38.0)$ & $85(62.0)$ & $1.5(1.0-2.2)$ & .059 \\
\hline
\end{tabular}

*Odds ratio adjusted for other significant factors; Obtained with a step-wise multiple logistic regression analysis.

spondents aged 18-39, the level of good attitude toward antibiotics was low in those aged 40-59 (OR 0.67; 95\% CI 0.51-0.89) (Table 5).

\section{DISCUSSION}

The results of this study demonstrate that the general public has misunderstandings and a lack of knowledge about antibiotics despite national educational campaigns addressing the appropriate use of antibiotics, in comparison to previous studies (Andre et al., 2010; McNulty et al., 2007a; McNulty, Boyle, Nichols, Clappison, \& Davey, 2007b; You et al., 2008). The majority of respondents in our study had correct knowledge as to the cause of common colds and coughs. However, the general public is not well informed as to the appropriate use of antibiotics, the meaning of antibiotic resistance and the spread of antibiotic resistant bacteria. In particular, 70\% of respondents did not know that antibiotics do not work on most coughs and colds in
Table 5. Factors Significantly Associated with Public Attitudes Toward Antibiotic Use

\begin{tabular}{|c|c|c|c|c|}
\hline & \multicolumn{2}{|c|}{$n(\%)$} & \multirow[b]{2}{*}{$\begin{array}{c}\text { Adjusted OR } \mathrm{R}^{*} \\
(95 \% \mathrm{Cl})\end{array}$} & \multirow[b]{2}{*}{$p$} \\
\hline & $\begin{array}{c}\text { Poor attitudes } \\
(<4) \\
(n=698)\end{array}$ & $\begin{array}{c}\text { Good attitudes } \\
\begin{array}{c}(\geq 4) \\
(n=404)\end{array}\end{array}$ & & \\
\hline \multicolumn{5}{|l|}{ Age (yr) } \\
\hline $18-39$ & $280(57.6)$ & $206(42.4)$ & 1 (Referent) & \\
\hline $40-59$ & $332(68.3)$ & $154(31.7)$ & $0.67(0.51-0.89)$ & .005 \\
\hline$\geq 60$ & 79 (65.3) & $42(34.7)$ & $1.21(0.69-2.13)$ & .516 \\
\hline \multicolumn{5}{|l|}{ Education } \\
\hline$\leq$ Primary & $53(70.7)$ & $22(29.3)$ & 1 (Referent) & \\
\hline Middle school & $64(83.1)$ & $13(16.9)$ & $0.51(0.22-1.19)$ & .093 \\
\hline High school & $303(63.8)$ & $172(36.2)$ & $1.35(0.67-2.71)$ & .444 \\
\hline$\geq$ College & $265(58.0)$ & $192(42.0)$ & $1.71(0.85-3.44)$ & .147 \\
\hline \multicolumn{5}{|c|}{ Exposure to campaign } \\
\hline No & $632(65.0)$ & $340(35.0)$ & 1 (Referent) & \\
\hline Yes & $66(51.2)$ & $63(48.8)$ & $1.76(1.19-2.58)$ & .004 \\
\hline \multicolumn{5}{|c|}{ Knowledge of antibiotic use } \\
\hline Inadequate & $338(70.9)$ & $139(29.1)$ & 1 (Referent) & \\
\hline Adequate & $357(57.4)$ & $265(42.6)$ & $1.52(1.16-2.00)$ & .003 \\
\hline
\end{tabular}

${ }^{*}$ Odds ratio adjusted for other significant factors; Obtained with a step-wise multiple logistic regression analysis.

comparison to a United Kingdom (UK) study (McNulty et al., 2007a) that found this proportion to be $38 \%$. In the same UK survey, $43 \%$ of respondents, compared to 57\% in our study, understood that antibiotics can kill bacteria that normally live on the skin and in the gut (McNulty et al., 2007a). Similarly, approximately two-thirds of respondents in our survey were unaware of the spread of antibiotic resistant bacteria or that not finishing a course of antibiotics could lead to antibiotic resistance.

In terms of attitude toward antibiotic use, our findings showed that $30 \%$ of respondents took antibiotics when they had a cold, which is similar to the findings (27\%) reported by Van den Eng and colleagues (2003). However, most respondents in our study had misunderstandings with respect to the effects of not completing an antibiotic treatment course when compared with similar surveys. In our study, 77\% of respondents reported that they would stop taking a course of antibiotics when they felt better, compared to $58 \%$ (You et al., 2008) and 13\% (McNulty et al., 2007b) in other surveys. Similarly, 48\% of respondents believed that taking antibiotics would lead to a quicker recovery, as compared to $32 \%$ in the UK study (McNulty et al., 2007a) and 19\% in a Swedish study (Andre et al., 2010).

The inadequate level of knowledge and poor attitude of respondents in our study seems to be related to the prevalent and inappro- 
priate use of antibiotics in Korea (Kim \& Park, 1998). The majority of respondents reported that they did not know whether or not the prescribed drugs included an antibiotic. This may be due in part to the nonchalant attitude toward Korean physicians with regard to prescribing antibiotics for URIs in addition to a lack of explanation provided to patients for the antibiotics they are prescribed (Kim et al., 2004). To reduce unnecessary or improper antibiotic use, a change in beliefs held by physicians as well as the general public is critical. Current public misconceptions could put people at unnecessary risk for infection with antibiotic-resistant bacterial pathogens.

Our results identified demographic groups with poor attitudes toward antibiotic use, including persons with low educational status and those aged 40-59. Groups with inadequate knowledge regarding antibiotic use included the elderly (aged $\geq 60$ ), and those of lower socioeconomic or educational status. As we found, a higher educational level has been associated with better knowledge and attitude (Parimi, Pereira, \& Prabhakar, 2004; Van den Eng et al., 2003; You et al., 2008), and the elderly are less knowledgeable about antibiotics in general (McNulty et al., 2007a). A unique finding in our study was that respondents aged $\geq 60$ had better attitudes than those aged 40-59, even though their knowledge of antibiotics was the lowest overall.

On the whole, respondents who had inadequate knowledge scores were more likely to have a poor attitude toward antibiotic use. More respondents with inadequate antibiotic knowledge than those with adequate knowledge demanded antibiotic prescriptions and were unable to identify the antibiotics among their prescribed drugs. Also, they more frequently believed that antibiotics would cure colds quickly. Multivariate analysis also showed adequate knowledge of appropriate antibiotic use was a predictor for a good attitude. Parimi et al. (2004) found that the antibiotic knowledge score did influence attitude and behavior. In that study, demanding antibiotic prescriptions and keeping these drugs at home to treat illness was higher in respondents with inadequate knowledge than in those with adequate knowledge. These findings support the idea that the provision of accurate and concrete information on antibiotics and the potential for antibiotic resistance can change attitudes and behaviors with regards to antibiotic use. An understanding of antibiotic use is important because personal decisions are based on these understandings (Norris et al., 2010). They can impact physicians' prescription behavior (Belongia, Naimi, Gale, \& Besser, 2002), as well as lead to decreasing suboptimal use of antibiotics, such as using short courses and sub-therapeutic doses (Norris et al.).

Educational campaigns by the KFDA are currently being undertaken with the goal of promoting a more judicious use of antibiotics and to prevent antibiotic resistance. Results of the present study revealed that only $12 \%$ of respondents had contact with a campaign. This result showed that the national educational campaign might not be considered successful as it was intended in terms of dissemination of education. The campaign needs to be restructured by user characteristics. However, the respondents exposed to the educational campaign had a good attitude toward antibiotic use. The multivariate analysis carried out in the present study showed exposure to the national educational campaign significantly affected attitude, while it did not affect knowledge level. This finding is similar to results reported by Curry et al. (2006) in which the percentage of the general public who understood that antibiotics are ineffective in the treatment of viral infections did not change, even though there was a reduction in those wanting antibiotics for specific symptoms. They suggested that people are aware that they should not be using antibiotics to treat colds, even if they do not know the reason.

Consistent and multifaceted intervention strategies concerning appropriate antibiotic use and the problems of antibiotic resistance are needed in order to correct widespread misconceptions on antibiotic use. The benefits of public campaigns present slowly over time, suggesting the need for continual reinforcement and repetition (Wutzke et al., 2006). Strategies including use of television, newspapers, and the internet are effective modalities for public education, considering transferring time zone (Finch, Metlay, Davey, \& Baker, 2004; Madle, Kostkova, Mani-Saada, Weinberg, \& Williams, 2004). The focus of interventions designed to change attitudes should be placed primarily on the adults aged 40-59 and those with lower education levels. Repeated information using short, tailored slogans and cues to action would improve general knowledge on antibiotics, especially in groups with lower educational levels (Marx, Nedelmann, Haertle, Dieterich, \& Eicke, 2008). Furthermore, if the aim is to reduce antibiotic use for URIs, then public education would work best when aligned with interventions aimed at physicians (Kiang et al., 2005; Wutzke et al., 2006). Educational campaigns including physicians have had a positive effect on knowledge and a reduction in the prescription of antibiotics (Kiang et al.; Wutzke et al.). Our study has several limitations. With respect to the impact of the national educational campaign, we examined knowledge and attitudes only after 
the national educational campaign, not before, making it difficult to detect any change over time. Additionally, it is difficult to pinpoint the direct effects of the national educational campaign as respondents may have been exposed to other information related to antibiotic use. Another limitation is that our results rely on reported rather than measured behavior. This is, however, the largest face-to-face survey of public knowledge and attitudes on antibiotic use after the national educational campaign in Korea. Reliability of attitudes in the present study was undesirable, used as tools to construct one would need to be carefully. But according to Nunnally (1978), if an instrument is in the early stages of development, particularly when dealing with measurement of a new construct, internal consistency reliabilities of .5 to .6 are sufficient. In terms of representativeness, we were able to minimize sampling error by collecting data from 1,177 respondents residing in seven major metropolitan cities in Korea using a stratified convenient sampling method. However, we did not weigh the data for the age- and sex- specific population, thus the data were unequal probability of selection. The approval of Institutional Review Board (IRB) was not obtained for this study. Since there is no anticipated risk associated with participation in this survey, the study may possibly be deemed an exemption from IRB review.

\section{CONCLUSION}

Our results show that the majority of the general public has misconceptions that include thinking of antibiotics as useful in the treatment of the common cold, and being ignorant of antibiotic effectiveness and resistance despite a national educational campaign. Many also have poor attitudes toward antibiotic use. However, the respondents exposed to the educational campaign have a good attitude toward antibiotic use.

\section{REFERENCES}

Andre, M., Vernby, A., Berg, J., \& Lundborg, C. S. (2010). A survey of public knowledge and awareness related to antibiotic use and resistance in Sweden. The Journal of Antimicrobial Chemotherapy, 65, 1292-1296. doi: $10.1093 / \mathrm{jac} / \mathrm{dkq} 104$

Belongia, E. A., Naimi, T. S., Gale, C. M., \& Besser, R. E. (2002). Antibiotic use and upper respiratory infections: A survey of knowledge, attitudes and experience in Wisconsin and Minnesota. Preventive Medicine, 34, 346-352. doi: 10.1006/pmed.2001.0992

Centers for Disease Control and Prevention. (2010, May 20). Get smart:
Know when antibiotics work on the farm. Retrieved April 13, 2010, from http://www.cdc.gov/narms/get_smart.htm

Curry, M., Sung, L., Arroll, B., Goodyear-Smith, F., Kerse, N., \& Norris, P. (2006). Public views and use of antibiotics for the common cold before and after an education campaign in New Zealand. The New Zealand Medical Journal, 119(1233), U1957

Dancer, S. J. (2004). How antibiotics can make us sick: The less obvious adverse effects of antimicrobial chemotherapy. The Lancet Infectious Diseases, 4, 611-619. doi: 10.1016/S1473-3099(04)01145-4

Farrell, D. J., Jenkins, S. G., Brown, S. D., Patel, M., Lavin, B. S., \& Klugman, K. P. (2005). Emergence and spread of streptococcus pneumoniae with erm (B) and mef (A) resistance. Emerging Infectious Diseases, 11, 851858.

Finch, R. G., Metlay, J. P., Davey, P. G., \& Baker, L. J. (2004). Educational interventions to improve antibiotic use in the community: Report from the International Forum on Antibiotic Resistance (IFAR) colloquium, 2002. The Lancet Infectious Diseases, 4, 44-53. doi: 10.1016/ S1473-3099 (03)00860-0

Kiang, K. M., Kieke, B. A., Como-Sabetti, K., Lynfield, R., Besser, R. E., \& Belongia, E. A. (2005). Clinician knowledge and beliefs after statewide program to promote appropriate antimicrobial drug use. Emerging Infectious Diseases, 11, 904-911.

Kim, N. S., Kim, D. S., Chang, S. M., Jung, H. J., Kim, C. G., Oh, H. S., et al. (2006). Analysis and evaluation of antibiotic use. Seoul: Korea Food and Drug Administration.

Kim, S. O., Kim, N. S., Ji, S. M., Woo, K. S., Song, H. J., \& Kim, E. J. (2004). Antibiotic use and related awareness of physician, pharmacist and consumer. Seoul: Korea Food and Drug Administration.

Kim, W., \& Park, S. (1998). Bacterial resistance to antimicrobial agents: An overview from Korea. Yonsei Medical Journal, 39, 488-494.

Kwon, K., Hwang, I. G., Kwak, H. S., Park, J. S., Kim, M. G., Lee, G., et al. (2006). Administration of national antimicrobial resistance experts and public campaign activities. Cheongwon: The Annual Report of Korea Food and Drug Administration.

Levy, S. B. (2005). Antibiotic resistance-the problem intensifies. Advanced Drug Delivery Reviews, 57, 1446-1450. doi: 10.1016/j.addr. 2005.04.001

Madle, G., Kostkova, P., Mani-Saada, J., Weinberg, J., \& Wiliams, P. (2004). Changing public attitudes to antibiotic prescribing: Can the internet help? Informatics in Primary Care, 12, 19-26.

Marx, J. J., Nedelmann, M., Haertle, B., Dieterich, M., \& Eicke, B. M. (2008). An educational multimedia campaign has differential effects on public stroke knowledge and care-seeking behavior. Journal of Neurology, 255, 378-384. doi: 10.1007/s00415-008-0673-5

McNulty, C., Boyle, P., Nichols, T., Clappison, P., \& Davey, P. (2007a). Don't wear me out- the public's knowledge of and attitudes to antibiotics use. The Journal of Antimicrobial Chemotherapy, 59, 727-738. doi: 10.1093/ $\mathrm{jac} / \mathrm{dk} 1558$

McNulty, C., Boyle, P., Nichols, T., Clappison, P., \& Davey, P. (2007b). The public's attitudes to and compliance with antibiotics. The Journal of Antimicrobial Chemotherapy, 60(supple1), i63-i68. doi: 10.1093/jac/dkm 161

Norris, P., Ng, L. F., Kershaw, V., Hanna, F., Wong, A., Talekar, M., et al. (2010). Knowledge and reported use of antibiotics amongst immigrant ethnic groups in New Zealand. Journal of Immigrant and Minority Health, 12, 
107-112. doi: 10.1007/s10903-008-9224-5

Nunnally, J. C. (1978). Psychometric theory. New York: McGraw-Hill Book Co. Parimi, N., Pereira, L. M. P., \& Prabhakar, P. (2004). Caregivers' practices, knowledge and beliefs of antibiotics in paediatric upper respiratory tract infections in Trinidad and Tobago: A cross-sectional study. BMC Family Practice, 5, 28. doi: 10.1186/1471-2296-5-28

Van den Eng, J., Marcus, R., Hadler, J., Hadler, J. L., Imhoff, B., Vugia, D. J., et al. (2003). Consumer attitudes and use of antibiotics. Emerging Infectious Diseases, 9, 1128-1135. doi: 10.3201/eid0909.020591

Woodhead, M., \& Finch, R. (2007). Public education: A progress report. The Journal of Antimicrobial Chemotherapy, 60(supple 1), i53-i55. doi: $10.1093 / \mathrm{jac} / \mathrm{dkm} 158$
World Health Organization. (2001). WHO global strategy for containment of antimicrobial resistance. Geneva: World Health Organization.

Wutzke, S., Artist, M., Kohoe, L., Fletcher, M., Mackson, J., \& Weekes, L. (2006). Evaluation of a national programme to reduce inappropriate use of antibiotics for upper respiratory tract infections: Effects on consumer awareness, beliefs, attitudes and behaviour in Australia. Health Promotion International, 22, 53-64. doi: 10.1093/heapro/dal034

You, J. H. S., Yau, B., Choi, K. C., Chau, C. T. S., Huang, O. R., \& Lee, S. S. (2008). Public knowledge, attitudes and behavior on antibiotic use: A telephone survey in Hong Kong. Infection, 36, 153-157. doi: 10.1007/ s15010-007-7214-5 